\title{
Augmentative Modelling: A Template for Populus spp. Stand Biomass in Eurasia Region
}

\section{1,2VLADIMIR, ANDREEVICH USOLTSEV,${ }^{1 *}$ SEYED OMID REZA SHOBAIRI, ${ }^{2}$ IVAN STEPANOVICH TSEPORDEY, ${ }^{1}$ VIKTOR PETROVICH CHASOVSKIKH}

\author{
${ }^{1}$ Ural State Forest Engineering University, 620100 Yekaterinburg, Sibirskiy Trakt, 37, Russia \\ ${ }^{2}$ Botanical Garden of Ural Branch of RAS, 620144 Yekaterinburg, ul. 8 Marta, 202a, Russia \\ *Corresponding Author Email: Omidshobeyri214@gmail.com
}

\begin{abstract}
Today, estimating of biological productivity or carbon-depositing ability of forests is going on the global level, and its increase is one of the major factors of climate stabilization. In recent years, two trends in the harmonization of allometric models of tree biomass have been developing. The first of them is related to ensuring the additivity of the biomass component composition, and the second one - to the search for the so-called generic model applicable to a wide range of environmental conditions. However, all "generic" models give significant biases in their application in local conditions. In our modeling, we adhere to the principle of biomass additivity, split "generic" model into regional variants by introducing dummy variables, and build the model at the transcontinental level for the first time. When using the unique in terms of the volume of database on the level of stand of the genus Populus spp. in a number of 212 sample plots, the trans-Eurasian additive allometric models of biomass of stands for Eurasian Populus forests are developed, and thereby the combined problem of model additivity and generality is solved. The additive model of forest biomass of Populus is harmonized in two ways: it eliminated the internal contradictions of the component and the total biomass equations, and in addition, it takes into account regional differences of forest stands not only on total, aboveground and underground biomass, but also on its component structure, i.e. it reflects the regional peculiarities of the component structure of biomass.
\end{abstract}

DOI: https://dx.doi.org/10.4314/jasem.v24i5.15

Copyright: Copyright (C) 2020 Vladimir et al. This is an open access article distributed under the Creative Commons Attribution License (CCL), which permits unrestricted use, distribution, and reproduction in any medium, provided the original work is properly cited.

Dates: Received: 29 March 2020; Revised: 27 April 2020; Accepted: 18 May 2020

Keywords: genus Populus spp., biomass of forests, allometric models, sample plots, biological productivity.

In recent years, the world forest ecology is experiencing unprecedented information splash in the assessment of forest biological productivity in relation to climate change observed since 1960-80-ies (Budyko 1977). The current hype surrounding the problem of breached the carbon balance of the biosphere passes into the common paradigm of sustainable development, which the first is biosphere-stabilizing function of forests, but traditional resource forest management is seen as a subordinate task (Utkin 1995). Estimating of biological productivity or carbondepositing ability of forests is going on the global level, and its increase is one of the major factors of climate stabilization. The modern methods of modelling the biological productivity of trees and tree stands have been developed towards additivity of biomass components (Bi et al. 2010, Dong et al. 2015) and towards transition from "pseudo-generic" allometric models to really generic, involving regionalization of biomass model by introducing dummy variables (Fu et al. 2012), that usually fulfilled on local sets of actual biomass of trees and tree stands. We generated the database of forest stand biomass for the main forest species in Eurasia (Usoltsev 2010), that has enabled these modern methodologies to be implemented on the entirely different, higher level, namely to begin modelling additive biomass on transcontinental level. In this article, the first attempt to develop transcontinental harmonized allometric model of vicar species aspen and poplar (genus Populus spp.) forest stand biomass, which combine both mentioned by Jacobs and Cunia (1980) approaches, namely, ensuring the principle of additivity of biomass component composition and localizing (dismemberment) of biomass additive model on regions of Eurasia by introducing dummy variables. In other words, an attempt is made to solve the problems of combining additivity and totality of models. These models will provide the basis for the development of trans-continental regional standards for evaluation biomass of forest stands.

\section{MATERIALS AND METHODS}

Of the database mentioned the material in a number of 212 sample plots with estimations of Populus forest stand biomass ( $\mathrm{t} / \mathrm{ha})$ is extracted. Genus Betula spp. is 
introduced by four species (correspondingly $P$. tremula L., $P$. alba L., $P$. laurifolia L., and $P$. davidiana $D$.), distributed across 10 eco-regions and designated respectively with the 10 dummy variables from $X_{0}$ to $X_{9}$ (Table 1). Analysis of biomass forest stands is made on the basis of allometric additive models. According to the structure of disaggregation three-step model (Tang et al. 2000; Dong et al. 2015), biomass value, estimated by the total biomass equation, exploded into components according to the scheme presented in Figure 1. The coefficients of the regression models for all three steps are evaluated simultaneously, which ensures additivity of biomass of all the components - total, intermediate (steps 1 and 2) and initial (step 3a,b) (Dong et al. 2015).

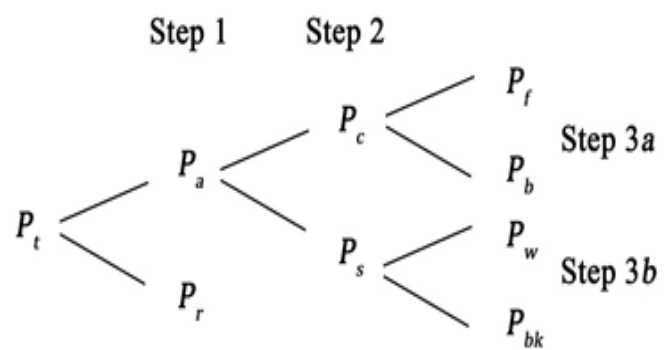

Fig. 1. The pattern of disaggregating three-step proportional weighting additive model. Designation: $P t, P r, P a, P c, P s, P f, P b$, $P w$ and $P b k$ are stand biomass respectively: total, underground (roots), aboveground, crown (needles and branches), stems above bark (wood and bark), needles, branches, stem wood and stem bark correspondingly, t per ha.

Table 1. The encoding scheme of the regional actual biomass data sets of 212 Populus forest stands.

\begin{tabular}{|c|c|c|c|c|c|c|c|c|c|c|c|c|c|c|c|}
\hline \multirow[t]{2}{*}{ Eco-region } & \multirow{2}{*}{$\begin{array}{l}\text { Species of } \\
\text { Populus sp. }\end{array}$} & Blo & $\mathrm{ck}$ of & dum & nmy & varic & ables & & & \multirow{2}{*}{\multicolumn{2}{|c|}{$\begin{array}{l}\text { Ranges of: } \\
\text { stand age, } \\
\text { yrs }\end{array}$}} & \multirow{2}{*}{$\begin{array}{l}\text { tree number, } \\
1000 / \text { ha }\end{array}$} & \multirow{2}{*}{$\begin{array}{l}\text { mean } \\
\text { diameter, } \\
\mathrm{cm}\end{array}$} & \multirow{2}{*}{$\begin{array}{l}\text { mean } \\
\text { height, } \\
\mathrm{m}\end{array}$} & \multirow[t]{2}{*}{$\begin{array}{l}\text { Plot } \\
\text { quantity }\end{array}$} \\
\hline & & $X_{1}$ & $X_{2}$ & $X_{3}$ & $X_{4}$ & $X_{5}$ & $X_{6}$ & $X_{7}$ & $X_{8}$ & & & & & & \\
\hline $\begin{array}{l}\text { West and Middle } \\
\text { Europe }\end{array}$ & P. tremula $\mathrm{L}$. & 0 & 0 & 0 & 0 & 0 & 0 & 0 & 0 & 0 & $3 \div 57$ & $0.64 \div 22.8$ & $1.9 \div 30.6$ & $2.1 \div 28.6$ & 61 \\
\hline $\begin{array}{l}\text { European part of } \\
\text { Russia, north }\end{array}$ & P. tremula $\mathrm{L}$. & 1 & 0 & 0 & 0 & 0 & 0 & 0 & 0 & 0 & $2 \div 85$ & $0.49 \div 92.0$ & $2.5 \div 33.0$ & $1.7 \div 31.0$ & 37 \\
\hline $\begin{array}{l}\text { European part of } \\
\text { Russia, south }\end{array}$ & P. tremula L. & 0 & 1 & 0 & 0 & 0 & 0 & 0 & 0 & 0 & $10 \div 50$ & $0.53 \div 30.0$ & $2.2 \div 25.2$ & $4.9 \div 24.0$ & 20 \\
\hline $\begin{array}{l}\text { European part of } \\
\text { Russia, south }\end{array}$ & P. alba $\mathrm{L}$. & 0 & 0 & 1 & 0 & 0 & 0 & 0 & 0 & 0 & $11 \div 68$ & $0.22 \div 12.5$ & $0.3 \div 34.7$ & $1.5 \div 26.0$ & 9 \\
\hline Western Siberia, taiga & P. tremula $\mathrm{L}$. & 0 & 0 & 0 & 1 & 0 & 0 & 0 & 0 & 0 & $6 \div 95$ & $0.57 \div 30.5$ & $2.1 \div 31.8$ & $3.2 \div 29.6$ & 14 \\
\hline $\begin{array}{l}\text { Western Siberia, } \\
\text { forest-steppe }\end{array}$ & P. tremula $\mathrm{L}$. & 0 & 0 & 0 & 0 & 1 & 0 & 0 & 0 & 0 & $10 \div 53$ & $0.41 \div 26.3$ & $2.3 \div 31.0$ & $4.0 \div 22.3$ & 26 \\
\hline Middle Siberia, north & P. tremula L. & 0 & 0 & 0 & 0 & 0 & 1 & 0 & 0 & 0 & $8 \div 140$ & $0.64 \div 22.8$ & $2.6 \div 23.8$ & $4.9 \div 24.5$ & 13 \\
\hline Middle Siberia, south & P. tremula L. & 0 & 0 & 0 & 0 & 0 & 0 & 1 & 0 & 0 & $21 \div 90$ & $0.80 \div 8.50$ & $6.2 \div 23.5$ & $7.4 \div 24.0$ & 11 \\
\hline Middle Siberia, south & P. laurifolia L. & 0 & 0 & 0 & 0 & 0 & 0 & 0 & 1 & 0 & $10 \div 120$ & $0.23 \div 7.87$ & $2.9 \div 38.3$ & $4.0 \div 25.3$ & 12 \\
\hline Japanese islands & P. davidiana $\mathrm{D}$. & 0 & 0 & 0 & 0 & 0 & 0 & 0 & 0 & 1 & $11 \div 33$ & $0.40 \div 1.24$ & $16.0 \div 35.6$ & $16.0 \div 23.8$ & 9 \\
\hline
\end{tabular}

\section{RESULTS AND DISCUSSION}

The initial allometric model is calculated;

$$
\ln P_{i}=a_{i}+b_{i}(\ln A)+c_{i}(\ln A)^{2}+d_{i}(\ln H)+e_{i}(\ln D)+f_{i}(\ln N)+\Sigma g_{i j} X_{j}
$$

where $P i$ - biomass of $i$-th component, t per ha; $A-$ stand age, years; $H$ - mean stand height, $\mathrm{m} ; D-$ mean tree diameter, $\mathrm{cm} ; N-$ tree number, $1000 / \mathrm{ha} ; a-g-$ regression coefficients; $i$ - index of biomass component: total (t), aboveground (a), roots (r), crowns (c), stems above bark (s), needles (f), branches (b), stem wood (w) and stem bark (bk); $j$ - index (code) in the block of dummy variables coding the ecoregions, from 0 to 9 (Table 1 ).

Model (1) after anti-log transformation is given to the form

$$
P_{i}=\mathrm{e}^{a i} A^{b i} A^{c i(\ln A)} H^{d i} D^{e i} N^{f i} e^{\Sigma g i j X j}
$$

Characteristic of equations (1) obtained by its approximation using actual biomass data, after the introduction of correction to the logarithmic transformation after Baskerville (1972) and the subsequent anti-log transformation to (2) are given as (3). All the regression coefficients of the equations (3) with numerical variables are significant at the level of probability of 0.95 or higher, and the equations are adequate to actual data. The equations (3) are modified according to the algorithm proposed by Chinese researchers (Dong et al. 2015) (Fig. 2), and the final transcontinental additive model of birch biomass component composition on the level of forest stand is given as (4). The model is valid in the range of actual data of stand age, mean tree height, mean stem diameter and tree density, listed in the Table 1, and is 
characterized by a double harmonization: one of which provides the principle of biomass component additivity, and the second one relates to the introduction of dummy variables, localizing the model according to ecoregions of Eurasia. Characteristic of initial allometric equations for Populus stands (3).

$P_{t}=-1.4525 A^{0.1895} H^{0.6266} D^{1.4217} N^{0.7278} \mathrm{e}^{-0.2124 X 1} \mathrm{e}^{-0.1116}$ $X^{2} \mathrm{e}^{-0.1329 X 3} \mathrm{e}^{0.1212 X 4} \mathrm{e}^{0.1124 X 5} \mathrm{e}^{-0.4512 X 6} \mathrm{e}^{-0.3754 X 7} \mathrm{e}^{-0.4461 X 8}$ $\mathrm{e}^{-0.1974 X 9} \cdot \operatorname{adj} R^{2}=0.941$;

\section{Step 1}

$P_{a}=-0.9172 A^{0.0643} H^{0.9428} D^{0.9816} N^{0.5133} \mathrm{e}^{-0.1788 X 1} \mathrm{e}^{-0.0480}$ $X 2 \mathrm{e}^{-0.1404 X 3} \mathrm{e}^{-0.0515 X 4} \mathrm{e}^{-0.1352 X 5} \mathrm{e}^{-0.3039 X 6} \mathrm{e}^{-0.0687 X 7} \mathrm{e}^{-0.3148 X 8}$ $\mathrm{e}^{-0.3746 X 9} \cdot \operatorname{adj} R^{2}=0.926$;

$P_{r}=-3.1790 A^{0.0063} H^{0.8556} D^{1.4371} N^{0.8408} \mathrm{e}^{-0.2610 X 1} \mathrm{e}^{-0.0147}$ $X 2 \mathrm{e}^{0.0393 X 3} \mathrm{e}^{0.4633 X 4} \mathrm{e}^{0.6511 X 5} \mathrm{e}^{-0.5738 X 6} \mathrm{e}^{-0.5135 X 7} \mathrm{e}^{-0.2593 X 8}$ $\mathrm{e}^{-0.0932 X 9} \cdot \operatorname{adj} R^{2}=0.884$;

\section{Step 2}

$P_{c}=-0.2793 A^{-0.1122} H^{0.1697} D^{1.1417} N^{0.3619} \mathrm{e}^{-0.2566 X 1} \mathrm{e}^{-0.0515}$ $X 2 \mathrm{e}^{-0.3327 X 3} \mathrm{e}^{-0.3194 X 4} \mathrm{e}^{-0.0632 X 5} \mathrm{e}^{-0.3539 X 6} \mathrm{e}^{0.0208 X 7} \mathrm{e}^{-0.5746 X 8}$ $\mathrm{e}^{-0.1100 X 9} \cdot \operatorname{adj} R^{2}=0.706$;
$P_{s}=-2.0633 A^{0.1132} H^{1.1110} D^{1.0832} N^{0.6234} \mathrm{e}^{-0.1603 X 1} \mathrm{e}^{-0.1541}$

$X 2 \mathrm{e}^{-0.0529 X 3} \mathrm{e}^{-0.0028 X 4} \mathrm{e}^{-0.1563 X 5} \mathrm{e}^{-0.2937 X 6} \mathrm{e}^{-0.1102 X 7} \mathrm{e}^{-0.2957 X 8}$ $\mathrm{e}^{-0.4256 X 9} \cdot \operatorname{adj} R^{2}=0.940$;

\section{Step 3a}

$P_{f}=-0.4315 A^{-0.5437} H^{0.3299} D^{0.9155} N^{0.3727} \mathrm{e}^{-0.0373 X 1} \mathrm{e}^{-0.0820}$

$X 2 \mathrm{e}^{-0.5233 X 3} \mathrm{e}^{-0.1438 X 4} \mathrm{e}^{-0.1601 X 5} \mathrm{e}^{-0.1982 X 6} \mathrm{e}^{0.3844 X 7} \mathrm{e}^{0.0527 X 8}$ $\mathrm{e}^{-0.5952 X 9} \cdot \operatorname{adj} R^{2}=0.625$;

$P_{b}=-1.4747 A^{0.1242} H^{0.1210} D^{1.2555} N^{0.4274} \mathrm{e}^{-0.3470 X 1} \mathrm{e}^{-0.0604}$

$X 2 \mathrm{e}^{-0.2422 X 3} \mathrm{e}^{-0.4023 X 4} \mathrm{e}^{-0.0553 X 5} \mathrm{e}^{-0.5191 X 6} \mathrm{e}^{-0.1626 X 7} \mathrm{e}^{-0.7813 X 8}$ $\mathrm{e}^{0.1811 \times 9} \cdot \operatorname{adj} R^{2}=0.741$;

\section{Step 3b}

$P_{w}=-2.6758 A^{0.2233} H^{1.3109} D^{0.8992} N^{0.6475} \mathrm{e}^{-0.2941 X 1} \mathrm{e}^{-0.1883}$

$X^{2} \mathrm{e}^{-0.2036 X 3} \mathrm{e}^{-0.2261 X 4} \mathrm{e}^{-0.1707 X 5} \mathrm{e}^{-0.2746 X 6} \mathrm{e}^{-0.1082 X 7} \mathrm{e}^{-0.3844 X 8}$ $\mathrm{e}^{-0.2004 X 9} \cdot \operatorname{adj} R^{2}=0.944$;

$P_{b k}=-3.0307 A^{0.1745} H^{0.7320} D^{1.0653} N^{0.6320} \mathrm{e}^{-0.2812 X 1} \mathrm{e}^{-0.1739}$ $X 2 \mathrm{e}^{0.2057 X 3} \mathrm{e}^{-0.3775 X 4} \mathrm{e}^{-0.2488 X 5} \mathrm{e}^{-0.4703 X 6} \mathrm{e}^{-0.3576 X 7} \mathrm{e}^{0.0061 X 8}$ $\mathrm{e}^{-0.1908 X 9} \cdot \operatorname{adj} R^{2}=0.900$;

Three-step additive model of biomass component composition for Populus forest stands, built by proportional weighing (4)

$P t=-1.4525 A^{0.1895} H^{0.6266} D^{1.4217} N^{0.7278} e^{-0.2124 X 1} e^{-0.1116 X 2} e^{-0.1329 X 3} e^{0.1212 X 4} e^{0.1124 X 5} e^{-0.4512 X 6} e^{-0.3754 X 7} e^{-0.4461 X 8} e^{-0.1974 X 9}$

Step 1

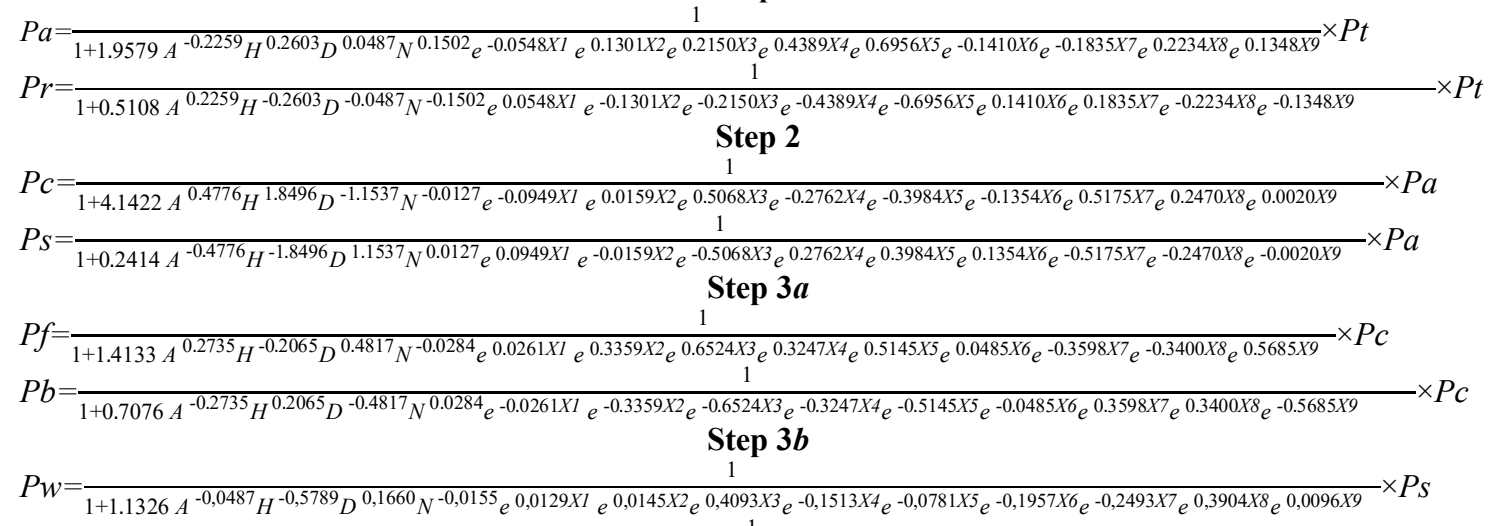

$P b k=\frac{1}{1+0,8829 A^{0,0487} H^{0,5789} D^{-0,1660} N^{0,0155} e^{-0,0129 X 1} e^{-0,0145 X 2} e^{-0,4093 X 3} e^{0,1513 X 4} e^{0,0781 X 5} e^{0,1957 X 6} e^{0,2493 X 7} e^{-0,3904 X 8} e^{-0,0096 X 9}} \times P s$

At the next stage of the study the comparison of the adequacy of additive model (4) and independent equations (3) is fulfiled. For their correct comparing the sample plots with incomplete biomass component structure are deleted from the initial harvest data, i.e. only those records are left in which the data are available on both aboveground and underground biomass. The equations (2) are approximated according to such "methodized" data, and their final forms are given as (5). The characteristics of "methodized" independent allometric equations for Populus stands (5).
$P_{t}=-1.4525 A^{0.1895} H^{0.6266} D^{1.4217} N^{0.7278} \mathrm{e}^{-0.2124 X 1} \mathrm{e}^{-}$ $0.1116 X 2 \mathrm{e}^{-0.1329 X 3} \mathrm{e}^{0.1212 X 4} \mathrm{e}^{0.1124 X 5} \mathrm{e}^{-0.4512 X 6} \mathrm{e}^{-0.3754 X 7}$ $\mathrm{e}^{-0.4461 X 8} \mathrm{e}^{-0.1974 X 9} \cdot \operatorname{adj} R^{2}=0.941$

Step 1

$P_{a}=-1.6237 A^{0.2322} H^{0.5953} D^{1.3884} N^{0.6906} \mathrm{e}^{-0.2062 X 1} \mathrm{e}^{-}$ $0.1448 X 2 \mathrm{e}^{-0.1757 X 3} \mathrm{e}^{0.0244 X 4} \mathrm{e}^{-0.0445 X 5} \mathrm{e}^{-0.4328 X 6} \mathrm{e}^{-0.3301 X 7}$ $\mathrm{e}^{-0.4827 X 8} \mathrm{e}^{-0.2281 X 9} \cdot \operatorname{adj} R^{2}=0.936$

$P_{r}=-3.1790 A^{0.0063} H^{0.8556} D^{1.4371} N^{0.8408} \mathrm{e}^{-0.2610 X 1} \mathrm{e}^{-}$ $0.0147 X 2 \mathrm{e}^{0.0393 X 3} \mathrm{e}^{0.4633 X 4} \mathrm{e}^{0.6511 X 5} \mathrm{e}^{-0.5738 X 6} \mathrm{e}^{-0.5135 X 7} \mathrm{e}^{-}$ $0.2593 \times 8 \mathrm{e}^{-0.0932 X 9} \cdot \operatorname{adj} R^{2}=0.884$

Step 2

$P_{c}=-0.6632 A^{-0.1791} H^{-0.8127} D^{2.3410} N^{0.7293} \mathrm{e}^{-0.1356 X 1}$ $\mathrm{e}^{-0.1705 X 2} \mathrm{e}^{-0.5251 X 3} \mathrm{e}^{0.2522 X 4} \mathrm{e}^{0.3068 X 5} \mathrm{e}^{-0.3045 X 6} \mathrm{e}^{-0.7258 X 7}$ $\mathrm{e}^{-0.6854 X 8} \mathrm{e}^{-0.2512 X 9} \cdot \operatorname{adj} R^{2}=0.769$ 
$P_{s}=-2.7471 A^{0.2985} H^{1.0369} D^{1.1873} N^{0.7166} \mathrm{e}^{-0.2305 X 1} \mathrm{e}^{-}$ $0.1547 X 2 \mathrm{e}^{-0.0183 X 3} \mathrm{e}^{-0.0240 X 4} \mathrm{e}^{-0.0916 X 5} \mathrm{e}^{-0.4398 X 6} \mathrm{e}^{-0.2084 X 7}$ $\mathrm{e}^{-0.4384 X 8} \mathrm{e}^{-0.2493 X 9} \cdot \operatorname{adj} R^{2}=0.942$

\section{Step 3a}

$P_{f}=-1.0533 A^{-0.3594} H^{-0.6045} D^{1.9471} N^{0.7628} \mathrm{e}^{-0.1921 X 1}$ $\mathrm{e}^{-0.4363 X 2} \mathrm{e}^{-1.0141 X 3} \mathrm{e}^{-0.0199 X 4} \mathrm{e}^{-0.1355 X 5} \mathrm{e}^{-0.4413 X 6} \mathrm{e}^{-0.4714}$ ${ }^{X 7} \mathrm{e}^{-0.4350 X 8} \mathrm{e}^{-0.6588 X 9} \cdot \operatorname{adj} R^{2}=0.585$

$P_{b}=-1.4887 A^{-0.0859} H^{-0.8110} D^{2.4288} N^{0.7343} \mathrm{e}^{-0.1660 X 1}$ $\mathrm{e}^{-0.1004 X 2} \mathrm{e}^{-0.3616 X 3} \mathrm{e}^{0.3048 X 4} \mathrm{e}^{0.3790 X 5} \mathrm{e}^{-0.3928 X 6} \mathrm{e}^{-0.8312 X 7}$ $\mathrm{e}^{-0.7750 X 8} \mathrm{e}^{-0.0903 X 9} \cdot \operatorname{adj} R^{2}=0.795$
Step 3b

$P_{w}=-2.6758 A^{0.2233} H^{1.3109} D^{0.8992} N^{0.6475} \mathrm{e}^{-0.2941 X 1} \mathrm{e}^{-}$ $0.1883 X 2 \mathrm{e}^{-0.2036 X 3} \mathrm{e}^{-0.2261 X 4} \mathrm{e}^{-0.1707 X 5} \mathrm{e}^{-0.2746 X 6} \mathrm{e}^{-0.1082 X 7}$ $\mathrm{e}^{-0.3844 X 8} \mathrm{e}^{-0.2004 X 9}$ adj $R^{2}=0.944$

$P_{b k}=-3.0307 A^{0.1745} H^{0.7320} D^{1.0653} N^{0.6320} \mathrm{e}^{-0.2812 X 1}$ $\mathrm{e}^{-0.1739 X 2} \mathrm{e}^{0.2057 X 3} \mathrm{e}^{-0.3775 X 4} \mathrm{e}^{-0.2488 X 5} \mathrm{e}^{-0.4703 X 6} \mathrm{e}^{-0.3576}$ $X 7 \mathrm{e}^{0.0061 X 8} \mathrm{e}^{-0.1908 X 9} \cdot \operatorname{adj} R^{2}=0.990$

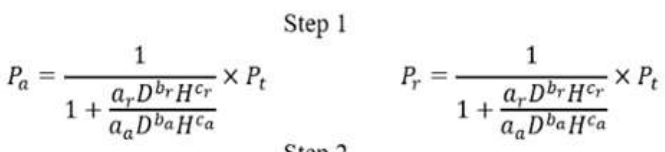

$$
\begin{aligned}
& P_{c}=\frac{1}{1+\frac{a_{s} D^{b_{s}} H^{c_{s}}}{a_{c} D^{b_{c}} H^{c_{c}}}} \times P_{a} \quad P_{s}=\frac{1}{1+\frac{a_{c} D^{b_{c}} H^{c_{c}}}{a_{s} D^{b_{s}} H^{c_{s}}}} \times P_{a} \\
& P_{f}=\frac{1}{1+\frac{a_{b} D^{b_{b} H^{c_{b}}}}{a_{f} D^{b_{f} H^{c_{f}}}}} \times P_{c} \quad P_{b}=\frac{1}{1+\frac{a_{f} D^{b_{f}} H^{c_{f}}}{a_{b} D^{b_{b}} H^{c_{b}}}} \times P_{c} \\
& P_{w}=\frac{1}{1+\frac{a_{b k} D^{b_{b k} H^{c_{b k}}}}{a_{w} D^{b_{w} H^{c_{w}}}}} \times P_{s}^{\text {Step } 3 b} \quad P_{b k}=\frac{1}{1+\frac{a_{w} D^{b_{w}} H^{c_{w}}}{a_{b k} D^{b_{b k}} H^{c_{b k}}}} \times P_{s}
\end{aligned}
$$

Fig. 2. The structure of three-step additive model built by proportional weighting (Dong et al., 2015). Symbols here and further see equation

As the "methodized" additive model, and "methodized" independent equations, are tabulated according to actual mass-forming indices of the modified data and the obtained values are compared with harvest biomass data using the formula:

$$
R^{2}=1-\frac{\sum_{i=1}^{N}\left(Y_{i}-\widehat{Y}_{i}\right)^{2}}{\sum_{i=1}^{N}\left(Y_{i}-\bar{Y}\right)^{2}} \quad 6
$$

Where $Y_{i}$ is observed value; $\hat{Y}_{i}$ is predicted value; $\bar{Y}$ is the mean of $N$ observed values for the same component.
The results of comparison of the adequacy of two modeling methods are summarized in the Table 2 and they indicate that the adequacy of the two systems of equations for aboveground biomass, underground one and stem biomass are similar and the indices of additive equations for mass of crown, needles and branches are slightly worse. This corresponds to the view (Cunia and Briggs 1984; Reed and Green 1985), that the correction of internal inconsistency of biomass equations by ensuring their additivity does not necessarily means improvements in the accuracy of

\begin{tabular}{|c|c|c|c|c|c|c|c|c|c|}
\hline \multirow{2}{*}{ Index } & \multicolumn{9}{|c|}{ Biomass components } \\
\hline & $P t$ & $P a$ & $P c$ & $P f$ & $\mathrm{~Pb}$ & $P r$ & $P_{S}$ & $P w$ & $P b k$ \\
\hline \multicolumn{10}{|c|}{ Independent equations } \\
\hline$R^{2}$ & 0.832 & 0.829 & 0.775 & 0.507 & 0.797 & 0.576 & 0.788 & 0.792 & 0.908 \\
\hline \multicolumn{10}{|c|}{ Additive equations } \\
\hline$R^{2}$ & 0.832 & 0.829 & 0.774 & 0.500 & 0.795 & 0.575 & 0.798 & 0.563 & 0.840 \\
\hline
\end{tabular}
biomass estimating.

Table 2. The comparison of adequacy indices of independent and additive equations for Populus stand biomass calculated with their regionalization by introducing dummy variables.

The ratio of actual values and derived ones by tabulating independent and additive stand biomass models (Figure 3 ) shows the degree of correlativeness of the actual and calculated values and, in many cases, the absence of visible differences in the structure of residual variances obtained on two named models. More or less the value of $\mathrm{R}^{2}$ of one or the other model is determined by the random position of actual values 
of maximum stand biomass in confidence range and uneven dispersion, namely accidental because of their
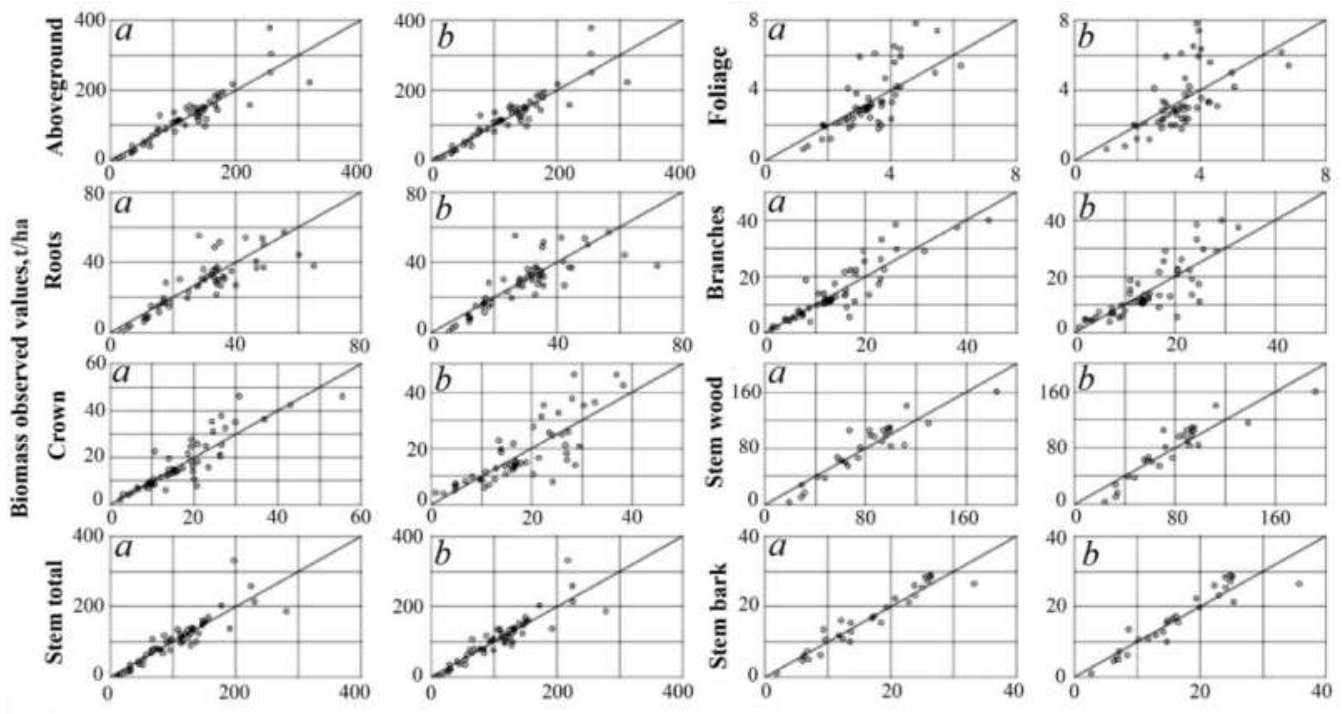

Biomass predicted values, $\mathrm{t} / \mathrm{ha}$

Fig. 3. The ratio of observed values and the values derived by calculation of independent (a) and additive (b) models of Populus stand biomass.

The additive model (4) includes four numeric independent variables. When it's tabulating, there is a problem, which is that we can know and give the value of stand age only of four variables, and the remaining three variables can be entered into the table in the form of calculated values obtained by the system of auxiliary recursive equations (Usoltsev 1989). Such equations are approximated using the original data as (7).

Characteristics of auxiliary recursive equations for mass-forming indices (7)

$H=0.6521+0.6922 \ln A-0.2786 X 1-0.3767 X 2-$ $0.9051 X 3-0.2697 X 4-0.3819 X 5-0.4924 X 6-0.4869$ $X 7-0.5463 X 8+0.7180 X 9 ;$ adj $R^{2}=0.694$

In $D=-1.1126+0.2345 \ln A+1.0652 \ln H-0.1042 X 1$ $+0.0873 X 2+0.2341 X 3-0.0549 X 4+0.0866 X 5-$ $0.1783 X 6+0.0033 X 7+0.1607 X 8+0.5308 X 9 ; \operatorname{adj}^{2}$ $=0.938$

In $N=3.6774-0.1809 \ln A+0.6000 \ln H-1.6102 \ln D$ $\pm 0.2832 X 1+0.2175 X 2-0.6512 X 3+0.2654 X 4$ $+0.2522 X 5+0.1768 X 6+0.6883 X 7+0.0698 X 8-$ $0.5215 X 9 ; \operatorname{adj}^{2}=0.867$

The results of sequential tabulations of the equations (7) and (4) give the unacceptably voluminous table, the size of which exceeds the format of journal article.
Therefore, a comparative analysis of the biomass structure of Populus stands of different ecoregions we limit by the stand age of 40 years (Table 3 ). According to the Table 3, the greatest values of total biomass (467 $\mathrm{t} / \mathrm{ha}$ ) correspond to plantations of $P$. davidiana in Japan and of $P$. tremula in West Europe growing in regions adjacent to the Pacific and Atlantic, and the lowest (71 $\mathrm{t} / \mathrm{ha}$ ) - to stands of poplar white in the steppe zone of southern Russia. Slightly higher biomass values - in aspen on the northern and southern limits of Central Siberia (92-97 t/ha), and in other regions of the Eurasian area the total biomass of aspen is within 161$255 \mathrm{t} / \mathrm{ha}$. The biomass indices of different ecoregions differed not only in absolute value but also in biomass ratios of different components; for example, the proportion of foliage in the aboveground biomass is maximum (3.7-4.1\%) at $P$. laurifolia and $P$. tremula in the South of Central Siberia, minimum one $(1.0 \%)$ in plantations of $P$. davidiana in Japan as well as at $P$. tremula in Western Europe and in the Turgay steppe $(1.9-2.0 \%)$, and in other regions of the Eurasian area is from 2.3 to $3.0 \%$.

Conclusion: When using the unique in terms of the volume of database on the level of a stand of the genus Populus sp., the trans-Eurasian additive allometric model of biomass for aspen and poplar forests is developed for the first time, and thereby the combined problem of model additivity and generality is solved. The model is harmonized in two levels, one of which 
provides the principle of additivity of biomass components, and the second one is associated with the introduction of dummy independent variables localizing model according to eco-regions of Eurasia. The proposed model and corresponding table for estimating stand biomass make them possible to calculate aspen and poplar stand biomass on Eurasian forests when using measuring taxation.

Table 3. Fragment of additive transcontinental table of Populus stand biomass for the age of 40 years, localized on the ecoregions of Eurasia.

\begin{tabular}{|c|c|c|c|c|c|c|c|c|c|c|c|c|c|}
\hline \multirow{2}{*}{ Region } & \multirow{2}{*}{ Species } & \multirow{2}{*}{$\begin{array}{c}H \\
\mathrm{~m}\end{array}$} & \multirow{2}{*}{$\begin{array}{l}D \\
\mathrm{~cm}\end{array}$} & \multirow{2}{*}{$\begin{array}{c}N, \\
1000 / \text { ha }\end{array}$} & \multicolumn{9}{|c|}{ Stand biomass, $\mathrm{t} / \mathrm{ha}$} \\
\hline & & & & & $P t$ & $\mathrm{~Pa}$ & $P c$ & $P f$ & $\mathrm{~Pb}$ & $P r$ & $P s$ & $P w$ & $P b k$ \\
\hline $\begin{array}{l}\text { West and Middle } \\
\text { Europe }\end{array}$ & P. tremula & 24.7 & 23.7 & 0.8 & 270.2 & 216.0 & 30.1 & 4.2 & 25.9 & 54.1 & 186.0 & 160.9 & 25.0 \\
\hline $\begin{array}{l}\text { European part of } \\
\text { Russia, north }\end{array}$ & P. tremula & 18.7 & 15.9 & 1.7 & 180.6 & 144.2 & 19.1 & 3.6 & 15.5 & 36.4 & 125.1 & 106.8 & 18.3 \\
\hline $\begin{array}{l}\text { European part of } \\
\text { Russia, south }\end{array}$ & P. tremula & 16.9 & 17.3 & 1.3 & 175.4 & 137.8 & 24.9 & 3.4 & 21.4 & 37.6 & 112.9 & 95.3 & 17.6 \\
\hline $\begin{array}{l}\text { European part of } \\
\text { Russia, south }\end{array}$ & P. alba & 10.0 & 11.4 & 0.8 & 46.9 & 38.1 & 8.2 & 0.9 & 7.3 & 8.8 & 29.8 & 22.1 & 7.7 \\
\hline $\begin{array}{l}\text { Western Siberia, } \\
\text { taiga }\end{array}$ & P. tremula & 18.8 & 16.9 & 1.5 & 255.0 & 175.2 & 19.5 & 3.5 & 16.1 & 79.7 & 155.7 & 135.9 & 19.9 \\
\hline $\begin{array}{l}\text { Western Siberia, } \\
\text { forest-steppe }\end{array}$ & P. tremula & 16.8 & 17.2 & 1.4 & 223.4 & 140.8 & 25.1 & 3.2 & 21.9 & 82.6 & 115.7 & 99.0 & 16.7 \\
\hline $\begin{array}{l}\text { Middle Siberia, } \\
\text { north }\end{array}$ & P. tremula & 15.1 & 11.8 & 2.2 & 97.3 & 80.9 & 12.2 & 2.4 & 9.8 & 16.3 & 68.7 & 59.8 & 8.9 \\
\hline $\begin{array}{l}\text { Middle Siberia, } \\
\text { south }\end{array}$ & P. tremula & 15.2 & 14.2 & 2.7 & 160.5 & 134.0 & 22.8 & 5.0 & 17.8 & 26.5 & 111.1 & 97.1 & 14.0 \\
\hline $\begin{array}{l}\text { Middle Siberia, } \\
\text { south }\end{array}$ & P. laurifolia & 14.3 & 15.6 & 1.2 & 91.6 & 72.5 & 11.0 & 3.0 & 8.0 & 19.1 & 61.5 & 47.6 & 13.9 \\
\hline Japanese islands & P. davidiana & 50.6 & 86.7 & 0.1 & 467.3 & 364.9 & 63.8 & 3.8 & 60.1 & 102.4 & 301.1 & 265.8 & 35.3 \\
\hline
\end{tabular}

Acknowledgment: The authors wish to acknowledge anonymous referees for their useful suggestions.

\section{REFERENCES}

Baskerville, GL (1972). Use of logarithmic regression in the estimation of plant biomass. Can. J. Forest Res. 2: 49-53.

Bi, H; Long, Y; Turner, J; Lei, Y.; Snowdon, P; Li, Y.; Harper, R; Zerihun, A; Ximenes, F (2010). Additive prediction of aboveground biomass for Pinus radiata (D. Don) plantations. Forest Ecol. Manage. 259: 2301-2314.

Budyko, MI (1977). Global ecology. Mysl' Publishing, Moscow, $328 \mathrm{p}$.

Cunia, T; Briggs, RD (1984). Forcing additivity of biomass tables: some empirical results. Can. J. Forest Res. 14: 376-384.

Dong, L; Zhang, L; Li, F (2015). A three-step proportional weighting system of nonlinear biomass equations. J. Forest Sci. 61(1): 35-45.

Fu, LY; Zeng, WS; Tang, SZ; Sharma, RP; Li, HK (2012). Using linear mixed model and dummy variable model approaches to construct compatible single-tree biomass equations at different scales-A case study for Masson pine in Southern China. J. Forest Sci. 58(3): 101-115.
Jacobs, MW; Cunia, T (1980). Use of dummy variables to harmonize tree biomass tables. Can. J. Forest Res. 10(4): 483-490

Reed, DD; Green, EJ (1985). A method of forcing additivity of biomass tables when using nonlinear models. Can. J. Forest Res. 15: 1184-1187

Tang, S; Zhang, H; Xu, H (2000). Study on establish and estimate method of compatible biomass model. Scientia Silvae Sinica 36: 19-27 (in Chinese with English abstract).

Usoltsev, VA (1989). Recurrent regression system as a base for tree and stand biomass tables. In: Proceedings of the IUFRO Project Group P3.05-00 Meeting "Harvesting and utilization of tree foliage", Riga, pp. 217-245. Available from: LVMI Silava: Rīgas iela 111, Salaspils LV-2169 Latvia.

Usoltsev, VA (2010). Eurasian forest biomass and primary production data. Ural Branch of Russian Academy of Sciences, $\quad$ Yekaterinburg, 574 p. (http://elar.usfeu.ru/handle/123456789/2606)

Usoltsev, VA (2013). Forest biomass and primary production database for Eurasia. CD-version. The second edition, enlarged and re-harmonized. Ural State Forest Engineering University, Yekaterinburg (http://elar.usfeu.ru/handle/123456789/3059). 